\title{
Students' Matriculation Factors for Higher Education in Private Universities of Bangladesh
}

\section{Md. Mizanur Rahman}

Senior Lecturer, Department of Business Administration, Metropolitan University, Sylhet, Bangladesh

\begin{abstract}
The main objective of this research paper is to identify the matriculation factors of students for higher education in private universities of Bangladesh. A survey was conducted among 750 students of fifteen UGC (University Grant Commission) approved private universities in Bangladesh. A structured questionnaire was sent to Dhaka, Sylhet, Rahshahi, and Chittagong division to collect data from selected private universities. A number of statistical measures (e.g. demographic analysis, descriptive analysis, multiple regression analysis) have been used to draw conclusions and offer recommendations. The results show that the common factors related to the matriculation factors of students are the image of the university, preferred program, quality of teaching, medium of instruction, campus size, location of the campus, hostel facility, transportation facility, canteen facility, common room facility, tuition fees for the students etc.
\end{abstract}

Key Words: Bangladesh, Higher education, Matriculation factors, Private University and Student.

JEL Classification Code: I20; I23

\section{INTRODUCTION}

The development of a country largely depends on the attainment of higher education. But unfortunately the attainment of higher education is very low. According to UGC (University Grant Commission) statistics of 2008, there are 84 universities in Bangladesh of which 31 are public, 2 are international and 51 are private universities. The number of students in the public universities is around 176969 and in the private universities are around 182641(UGC: 2008). Due to some limitations of public universities (limited enroll capacity, political unrest, excessive time etc.), in mid-1990's a large number of private universities emerged to fulfill the demand for the higher education. During the period of 1991 to 1996, sixteen private universities were opened (14 were in Dhaka and 02 were in Chittagong).But during 1996 to 2001 the condition was not favorable to build huge private universities. At that time only four new private universities were built. After 2001, the growth of private universities got a boost again. In 2001, According to BANBEIS, the total number of enrolled students in private universities increased from 27245 to 124267 in 2006. Debnath (2007) mentioned that almost 100,000 students themselves admitted into the private universities each year. In recent years the students' matriculation in higher education at private universities has been rapidly growing due to some significant factors. Age is one of the 
most important factors for students for matriculation of higher education in private universities in Bangladesh. In public as well as national universities it takes seven to eight years to complete the higher education. But from the private university they can complete their higher education within five years. Another important factor is credit transfer facility from one university to another university even though foreign university. We know that tuition fees of the private universities are generally high but most of the private universities offer a handsome waiver for the meritorious students and some of the universities offer special scholarship for poor students. Good and political unrest free environment is another important factor for higher matriculation in private universities of Bangladesh.

\section{Objectives of the Study}

The fundamental objective of this study is to investigate the matriculation behavior of the students' of private universities in Bangladesh. In order to emerge the fundamental objective, the researcher has considered the following objectives:

- To identify the market share of the students in private universities in Bangladesh.

- To know the demographic information of the students of private universities in Bangladesh.

- To determine the matriculation factors of the students of private universities in Bangladesh.

\section{Research Methodology}

The total sample of this research paper was the students' of the private universities in Bangladesh. A structured questionnaire was used to conduct this study. The questionnaire was classified into two parts to collect two types of information like

- To find out the demographic information of students

- To identify the matriculation factors of students.

To collect the information relating to demographic information of the students' a set of multiple choice questions had been developed and for collecting the information relating the matriculation behavior, 25 factors had been identified and a five-point "Likert Type" scale was applied. The five-point scale indicated 5 as "strongly agree" while 1 meant "strongly disagree". The questionnaire was pre-tested on the students" of the Metropolitan University, Sylhet. And finally, data were collected from 750 students during the autumn session of 2011 at fifteen UGC (University Grant Commission) approved private universities. To verify the collected data several statistical analyses and tests i.e., descriptive analysis, multiple regression analysis were conducted.

\section{Hypothesis Testing}

Hypothesis 01: The mean observation (image of the university) about the population is equal to 4.38 .

Hypothesis 02: There is no difference among the factors to the matriculation behavior of students' for higher education in private universities of Bangladesh.

\section{Literature Review}

The progress of higher education in this country (Bangladesh) has largely been due to the rapid growth of private universities in recent years. Rezwanul Huque Khan et all (2009), mentioned "Students are considered as the customers of the university" So it is very essential for a university to focus first on their targeted customers and ensuring the quality education. The quality education depends on some factors. Mamun and Das (1996) 
undertook a study and pointed towards some other attracting factors such as library facilities, laboratory facilities and internship assistance for students as the key factors of students' choice of private universities. On the other hand Andaleeb (2003) analyzed seven issues crucial for effectively fostering higher education in Bangladesh, namely teaching quality, method, content, peer quality, direct facilities, indirect facilities and political climate. Majid, Mamun, and Siddique (2009) found the similar factors mentioned above and they identified teaching quality, teaching learning methodology, teaching aids and support facilities as the basic selection factors of business education in private institutions. On another research studied by Zahid, chowdhury and sogra(2009), and mentioned and extensive qualitative study of performance of business education in Bangladesh and identified the course system, quality of teaching, medium of instruction, campus size and location, accommodation for the students, campus facilities such as auditorium , parking, canteen, indoor and outdoor parking facilities as the factors of satisfaction.

Tuition fees are one of the important factors for the students to enroll themselves as a student of private university. For this reason Salahuddin et all (2008) mentioned that "it is obvious that students do consider cost and cost related factors more than anything else because private university education is still very expensive from an economic perspectives and a significant number of students are from middle-class families. On the other sense Schofield (1996), mentioned that tuition fees as the main factor affecting a student's choice of a private university in Bangladesh as the tuition fees of these universities very widely here. We everybody know that Bangladesh is a developing country and most of the students do not have any opportunity to engage themselves in any earning source. So they have to depend on their parents to pay their tuition fees. Sometimes it is considered as burden to the guardian who bears the educational expenses. Another important factor mentioned by Rezwanul Huque khan and et all (2009), that parents' decision has been considered as the selection factors of private university.

Thus the matriculation factors regarding private universities found from the literature review as few factors that may motivate the students to choose a university. In this case the researcher has focused some factors which are the lower tuition fees, library and laboratory facilities, location of the campus, market oriented subjects, credit transfer facility, and hostel facility for the students, common room facilities for the students, brand value of the university, parents' decision and approved by UGC (University Grant Commission).

\section{Empirical Findings and Analysis}

Table: 01 Demographic Analysis of the students

\begin{tabular}{|c|c|c|c|c|}
\hline Variable & Categories & $\begin{array}{c}\text { Total } \\
\text { Respondents }\end{array}$ & $\begin{array}{c}\text { No. of } \\
\text { Responses }\end{array}$ & Percentages \\
\hline \multirow{5}{*}{ Age } & Below -19 Years & \multirow{5}{*}{750} & 13 & $01.73 \%$ \\
\hline & 19-23 Years & & 491 & $65.47 \%$ \\
\hline & 24-28 Years & & 169 & $22.54 \%$ \\
\hline & 29-33 Years & & 47 & $06.26 \%$ \\
\hline & 33 Years- Above & & 30 & $04.00 \%$ \\
\hline \multirow{4}{*}{$\begin{array}{l}\text { Guardian } \\
\text { Income }\end{array}$} & Below-25,000 & \multirow{4}{*}{750} & 44 & $05.93 \%$ \\
\hline & $25,000-40,000$ & & 338 & $45.06 \%$ \\
\hline & $40,000-55000$ & & 222 & $29.54 \%$ \\
\hline & 55000- Above & & 146 & $19.47 \%$ \\
\hline
\end{tabular}




\begin{tabular}{|c|c|c|c|c|}
\hline \multirow{2}{*}{\multicolumn{5}{|c|}{\begin{tabular}{|l|l|} 
& \\
\end{tabular}}} \\
\hline & & & & \\
\hline \multirow{4}{*}{$\begin{array}{c}\text { Passing } \\
\text { Group } \\
\text { in HSC }\end{array}$} & Science & \multirow{4}{*}{750} & 294 & $39.20 \%$ \\
\hline & Business Studies & & 278 & $37.07 \%$ \\
\hline & Humilities & & 102 & $13.60 \%$ \\
\hline & Others & & 76 & $10.13 \%$ \\
\hline & & & & \\
\hline \multirow{5}{*}{ Religion } & Islam & \multirow{5}{*}{750} & 667 & $88.93 \%$ \\
\hline & Hindu & & 53 & $07.07 \%$ \\
\hline & Christian & & 15 & $02.00 \%$ \\
\hline & Buddhist & & 12 & $01.60 \%$ \\
\hline & Others & & 03 & $0.40 \%$ \\
\hline
\end{tabular}

The table shows the demographic information of the students. The demographic information of students' is designed on the basis of four important variables: Age, Guardian Income, Passing group in HSC (Higher Secondary Certificate) and Religion. The result on respondent's "Age" states that almost $65.47 \%$ students' age range between 19-23 years and $22.54 \%$ of the students are in the range of $24-28$ years. So it can be said that most of the undergraduate students' age range is 19-23 years. The findings regarding the "Guardian Monthly Income" demonstrates that almost $45.06 \%$ students' guardian average monthly income is more than BDT 25000 but less than BDT 40000 which indicates that most of the students of the private universities come from middle class family. On the other hand $29.54 \%$ students' guardian average monthly income is more than BDT 40000 which indicates that a large portion of students' come from upper middle class family. This study also represents that $39.20 \%$ students' who are studying in private universities had their educational background in HSC (Higher Secondary Certificate) level in science , 37.07\% students' educational background had business studies , $13.60 \%$ had humilities group and rest $10.13 \%$ of the students' are from other educational background like A level, Vocational and Madrasa etc. It has also been found from the research that $88.93 \%$ students have come from Muslim family while $07.07 \%$ of the students have come from Hindu family and $2 \%$, $1.60 \%$ and $0.4 \%$ respectively from Christian, Buddhist and Other religions.

\section{Students Matriculation at Different Arenas of Study}

\section{Preferred Programs (For Undergraduate Students)}

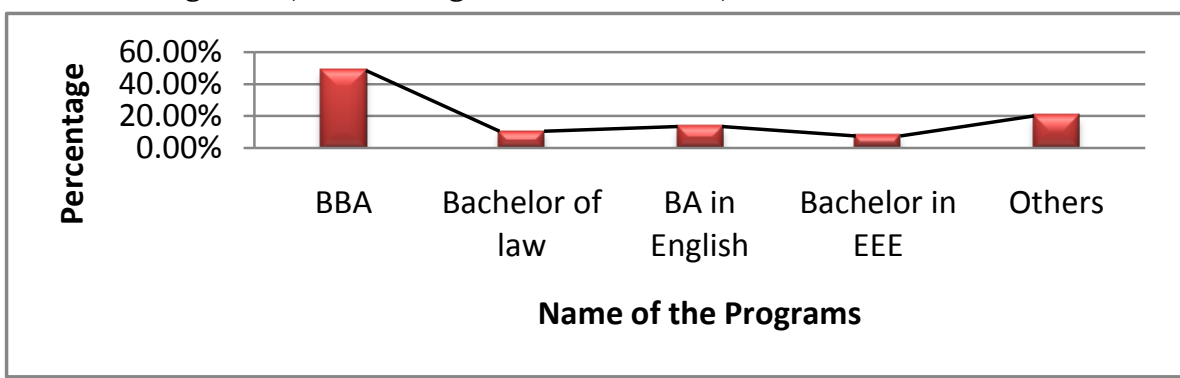

The figure represents top undergraduate program for the students. The findings of the study show that majority of the students $(48.43 \%)$ have been studying in BBA program followed by BA in English (13.43\%), Bachelor of Law (10.51\%), Bachelor of EEE (7.54\%) and other program $(20.06 \%)$. So it is clear that in terms of selecting preferred program BBA gets high priority than others program because the students in private universities think 
that the demand of BBA program is increasing day by day and after completing BBA program it is easy to manage a demandable job.

\section{Preferred Programs (For Post Graduate Students)}

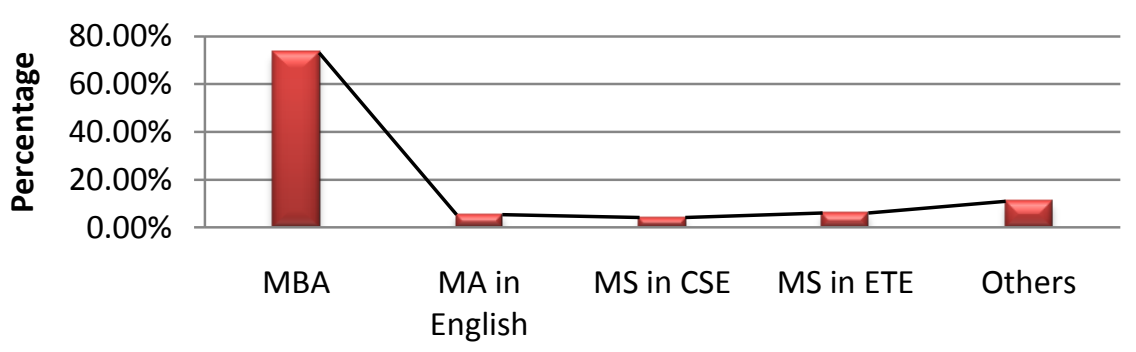

Name of the Programs

The figure represents top post graduate program for the students. The findings of the study show that majority of the students $(73.12 \%)$ have been studying in MBA program followed by MS in ETE (Electronics and Telecom Engineering) (06.15\%), MA in English $(05.45 \%), M S$ in CSE (Computer Science and Engineering) $(04.25 \%)$ and other program $(11.03 \%)$. So it is clear that in terms of selecting preferred program MBA program gets high priority than others program.

\section{Descriptive Statistics}

Table: 02 Descriptive Statistics of Students' Matriculation Factors

\begin{tabular}{|l|l|c|c|c|c|c|}
\hline $\mathbf{N o}$ & $\begin{array}{l}\text { Students' Matriculation Facrtors/ } \\
\text { Independent Variable }\end{array}$ & $\begin{array}{c}\text { Total } \\
\text { Respo } \\
\text { nses }\end{array}$ & $\begin{array}{c}\text { Total } \\
\text { Respon } \\
\text { dents }\end{array}$ & Mean & SD & CV \\
\hline $\mathbf{1 .}$ & Permanent campus & 3263 & 750 & 4.35 & 0.57 & 0.33 \\
\hline $\mathbf{2 .}$ & Location of the campus & 3092 & 750 & 4.12 & 0.69 & 0.48 \\
\hline $\mathbf{3 .}$ & Library facility (Books, Journals, etc.) & 2665 & 750 & 3.55 & 1.06 & 1.13 \\
\hline $\mathbf{4 .}$ & Parents decision & 3057 & 750 & 4.08 & 0.61 & 0.37 \\
\hline $\mathbf{5 .}$ & Computer lab & 2101 & 750 & 2.80 & 1.15 & 1.13 \\
\hline $\mathbf{6 .}$ & Image of the university & 3300 & 750 & 4.40 & 0.55 & 0.30 \\
\hline $\mathbf{7 .}$ & Preferred program & 3280 & 750 & 4.37 & 0.56 & 0.31 \\
\hline $\mathbf{8 .}$ & Classroom facility & 2962 & 750 & 3.95 & 0.67 & 0.45 \\
\hline $\mathbf{9 .}$ & Canteen facility & 1977 & 750 & 2.64 & 1.09 & 1.19 \\
\hline $\mathbf{1 0 .}$ & Common room & 2658 & 750 & 3.54 & 1.05 & 1.11 \\
\hline $\mathbf{1 1 .}$ & Laboratory facility & 1988 & 750 & 2.65 & 0.99 & 0.99 \\
\hline $\mathbf{1 2 .}$ & Hostel facility & 3250 & 750 & 4.33 & 0.59 & 0.35 \\
\hline $\mathbf{1 3 .}$ & Indoor games facility & 2007 & 750 & 2.68 & 1.10 & 1.21 \\
\hline $\mathbf{1 4 .}$ & Prayer room & 2351 & 750 & 3.13 & 0.96 & 0.93 \\
\hline $\mathbf{1 5 .}$ & Medical facility & 2011 & 750 & 2.68 & 1.09 & 1.19 \\
\hline $\mathbf{1 6 .}$ & Transportation facility & 3156 & 750 & 4.21 & 0.62 & 0.38 \\
\hline
\end{tabular}




\begin{tabular}{|l|l|c|c|c|c|c|}
\hline $\mathbf{1 7 .}$ & Auditorium & 2184 & 750 & 2.91 & 1.20 & 1.44 \\
\hline $\mathbf{1 8 .}$ & Credit transfer facility & 3224 & 750 & 4.30 & 0.60 & 0.36 \\
\hline $\mathbf{1 9 .}$ & Cultural club & 2007 & 750 & 2.68 & 1.10 & 1.21 \\
\hline $\mathbf{2 0 .}$ & Social \& academic status of the VC & 2643 & 750 & 3.52 & 0.53 & 0.28 \\
\hline $\mathbf{2 1 .}$ & Quality of teaching & 3267 & 750 & 4.36 & 0.58 & 0.33 \\
\hline $\mathbf{2 2 .}$ & Freedom to choose the major subject & 2645 & 750 & 3.53 & 1.06 & 1.12 \\
\hline $\mathbf{2 3 .}$ & Discussion room & 2075 & 750 & 2.77 & 1.13 & 1.28 \\
\hline $\mathbf{2 4 .}$ & Wash Room facility & 2141 & 750 & 2.85 & 1.16 & 1.34 \\
\hline $\mathbf{2 5 .}$ & Tuition fees & 3034 & 750 & 4.05 & 0.62 & 0.38 \\
\hline
\end{tabular}

Students were asked about 25 important factors relating to university, whether they were influenced by those factors and to what extent. Based on their answers (Mean, Standard deviation and Co-efficient of variance), it is observed that students are highly influenced by image of the university, preferred program, and quality of teaching (Table: 02). Majority of students consider an important factor that is permanent campus including some facilities like hostel facility, credit transfer facility, transportation facility, class room facility, common room facility, laboratory facility, medical facility, auditorium facility, wash room facility etc. From the above table it is found that location of the campus, parent's decision and tuition fees have significant impact to the enrolment factors of private universities of Bangladesh. After analyzing the descriptive statistics the researchers have found maximum number of students at various private universities in Bangladesh think that image of a university is very important along with preferred program and permanent campus to enroll them as a student of a university especially a private university. So the researcher has decided to conduct a hypothesis testing regarding image of the university and tried to show the relationship independent variables (25 factors) and dependent variable (students' matriculation).

\section{Hypothesis Testing}

Hypothesis Testing: The mean observation (image of the university) about the population is equal to 4.38 .

A sample of 750 students' is found to have a mean observation about image of the university is 4.40 . Can it be reasonably regarded as a sample from a large population with mean observation about image of the university is 4.38 and Standard deviation is 0.31 ? Test at $5 \%$ level of significance.

Taking the null hypothesis that the mean observation (Image of the university) about the population is equal to 4.38 , so we can write:

$$
\begin{aligned}
& \mathrm{H}_{0}: \mu \mathrm{H}_{0}=4.38 \\
& \mathrm{Ha}: \mu \mathrm{Ho} \neq 4.38
\end{aligned}
$$

And the given information as $\bar{X}=4.40, \sigma p=0.31, \mathrm{n}=750$ Assuming the population to be normal, we can work out the test statistic $Z$ as under

$$
\begin{aligned}
Z & =\frac{\bar{X}-\text { ?] } 0}{\frac{\sigma p}{\sqrt{n}}} \\
& =1.81
\end{aligned}
$$

As $\mathrm{Ha}$ is two-sided in the given question, we shall be applying a two-tailed test for determining the rejection regions at $5 \%$ level of significance which comes to as under, using normal curve area table:

$$
\mathrm{R}: \mathrm{Z}|<| 1.96
$$

The observed value $\mathrm{Z}$ is 1.81 which is less than the table value of $\mathrm{Z}$ and thus the null 
hypothesis is accepted. So it may conclude that the given sample (Image of the university $=4.40$ ) can be regarded to have been taken a population with mean observation about image of the university 4.38 and standard deviation 0.31 at $5 \%$ level of significance. Hypothesis Testing: There is no difference among the factors to the matriculation factors of students for higher education in private universities of Bangladesh.

\section{Multiple Regression Analysis}

As in our research, there are more than two independent variables, so the researchers have thought multiple regression analysis would be an ideal analysis.

From the appendix $=01$

$\mathrm{Y}($ Stu_Enr $)=\beta \mathrm{i}-.005($ Par_Cam $)+.001($ Loc_Cam $)+.002($ Lib_Fac $)+004($ Parn_Dec $)+.009$ $($ Com_Lab) +.959 (Img_uni) -.010 (Pre_Prog) -.013 (Cls_Fac) + .004 (Can_Fac) +.006 (Com_Fac) -.001 (Lab_Fac) -.019 (Host_Fac) $\beta 1$-.004 (Ind_Fac) -.014 (Pray_Fac) -.074 (Med_Fac) -.011 (Tran_Fac) -.011 (Audit_Fac) + .021 Crd_Tran) +.067 (Cul_Club) -.014 (Sta_VC) + .026 (N.Qul_Tc) -.006 (Maj_Sub) +.012 (Dis_Room) +.004 (Wash_Room) +.009 (Tut_Fees)

\begin{tabular}{|l|l|}
\hline Y: Student Matriculation & Ind_Fac=Indoor Game Facility \\
$\beta$ i: Constant & Pray_Fac=Prayer Room Facility \\
Par_Cam= Permanent Campus & Med_Fac=Medical Facility \\
Loc_Cam=Location of the Campus & Tran_Fac= Transportation Facility \\
Lib_Fac=Library Facility & (Audit_Fac= Auditorium Facility \\
Par_Dec= Parents Decision & Crd_Tran= Credit Transfer Facility \\
Com_Lab=Computer Lab & Cul_Club=Cultural Club \\
Img_Uni=Image of the University & Sta_VC=Status of Vic-chancellor \\
Cls_Fac=Class Room Facility & N.Qul_T=No of qualified teachers \\
Can_Fac=Canteen Facility & Maj_Sub= Major Subjects \\
Com_Fac=Common Room Facility & Dis_Room= Discussion Room \\
Lab_Fac=Labrotary Facility & Wash_Room=Wash room Facility \\
Host_Fac=Hostel Facility & Tut_Fees= Tuition Fees \\
\hline
\end{tabular}

The researcher has assumed the null hypothesis $\left(\mathrm{H}_{0}\right)$, there is no difference among the factors to the matriculation factors of the students' for higher education in private university of Bangladesh whereas alternative hypothesis (Ha) is that there are some differences among the factors the factors to the enrolment behavior of the students' for higher education in private university of Bangladesh.

The researcher assumes the $\beta$ values of each independent variable as group parameters. If the $\beta$ of all independent variable is same it indicates the independent variables ( 25 factors) have no effect on the dependent variable (student matriculation) which means the null hypothesis would be accepted. But if the $\beta$ of all the independent variables are not same then it can be said that the null hypothesis is rejected and automatically the alternative hypothesis would be accepted. From the above relationship, it is clear that the $\beta$ value associated with each independent variable is not same, that means the null hypothesis is rejected and alternative hypothesis is accepted for the matriculation factors of the students' for higher education in private universities of Bangladesh.

The researcher also uses the $\mathrm{R}^{2}$ value to the test hypothesis. If this value is 0 , then it can be said that there is no relationship among the independent and dependent variables for the 
matriculation factors of the students' for higher education in private universities of Bangladesh. If not, then we can say there is some relationship among the variables, which means it can reject the null hypothesis and accept alternative hypothesis.

Description of the hypothesis with multiple regression analysis given below:

\begin{tabular}{|l|}
\hline $1^{\text {st }}$ method using $\beta$ \\
\hline$\beta 1=\beta 2=\beta 3=\beta 4=\beta 5=\beta 6=\beta 7=\beta 8=\beta 9=\beta 10==\beta 11=\beta 12=\beta 13=\beta 14=\beta 15=\beta 16=\beta 17=\beta 18=\beta 19=\beta$ \\
$20=\beta 21=\beta 22=\beta 23=\beta 24=\beta 25=0$ \\
\hline $1^{\text {st }}$ method using R R value \\
\hline \multicolumn{2}{|c|}{ H0: $^{2}=0 \quad$ H0: $R^{2} \neq 0$} \\
\hline
\end{tabular}

From the result shown in the SPSS analysis for regression analysis, the following relationship was found for the independent and dependent variables-

Model Summary

\begin{tabular}{|l|c|r|r|r|}
\hline Model & R & R Square & $\begin{array}{c}\text { Adjusted R } \\
\text { Square }\end{array}$ & $\begin{array}{c}\text { Std. Error of } \\
\text { the Estimate }\end{array}$ \\
\hline 1 & $.961(\mathrm{a})$ & .924 & .921 & .15481 \\
\hline
\end{tabular}

Here,

$\mathrm{R}^{2}$ value $=0.924$

Adjusted $\mathrm{R}^{2}=0.921$

Also $R^{2} \neq 0$ which also means that the null hypothesis can be rejected and alternative hypothesis can be accepted. So, the hypothesis test can be done in both ways and result would be the same; rejection of null hypothesis and acceptance of alternative hypothesis. So, it can conclude that there are some relationships among the variables.

\section{Conclusion}

This study furnishes with some useful information for both business and academic community who are either involved or intense to get involved into higher education in private sectors. The development of a country largely depends on the attainment of higher education and this research paper shows a real picture of the matriculation factors of as well as Matriculation rate of higher education in private universities in Bangladesh. The matriculation rate in private universities of Bangladesh is increasing day by day. Out of them most of the students come from muslim family and their education expenses totally depends on their guardian income. Majority of the students studying in private universities had science in HSC level and the percentage of the students from other (Madrasa and English) background is very lower. The students mostly prefer BBA program followed by Bachelor of Arts in English and Bachelor of Law program. It also shows that in Post Graduate level more than half of the students are in MBA program followed by MA in English, MS in CSE( Computer Science and Engineering), MS in ETE( Electronic and Telecom Engineering). This research paper also indicates that there is a significant relationship between image of the university and permanent campus. That means the private universities who have their own campus including quality of teaching, medium of instructions, campus size, location of the campus, hostel facility for female, 
transportation facility, canteen facility, common room facility for the students etc get some benefits to enroll the students. This study indicates some important factors relating to the matriculation factors such as image of the university, preferred programs, permanent campus, tuition fees, parent's decisions, quality of teaching etc.

\section{Recommendations}

The overall education rate is increasing day by day so the market share of the students will be increased. So the authority of the private universities should give special attention to the students in following specific important areas.

a. The authority of the private universities should focus on BBA, English, law (Undergraduate Level), MBA and MA in English (Graduate Level).

b. They should consider the quality of teaching including full time qualified teachers and modern teaching aids.

c. To give some special offers for the students' who passed from other discipline (Madrasa, Vocational, etc.)

d. To organize special scholarships for poor meritorious students.

e. Keep political unrest free environment as much as possible.

f. The authority of the private universities should focus on permanent campus including library and laboratory facilities, location of the campus, market oriented subjects, credit transfer facility, hostel facility, and common room facilities for the students.

\section{Acknowledgement}

I would like to mention the contribution of all those who have inspired, influenced and helped me on the way of completing this research paper. First of all, my deepest and sincere gratitude goes to my honorable teacher as well as elder brother Mr. Saifur Rahman Buyhian, assistant professor, Department of Business Administration, Metropolitan University, Sylhet, who has given me the opportunity to go through the processes of this paper. I also wish to acknowledge my honorable teacher Dr. Taher Billal Khalifa, dean, Department of Business Administration who also inspired and influenced me to continue the research activities along with all of my respected teachers of Department of Business Administration for their suggestions and kind co-operations. At last I want to give a special thanks to my younger brother Md. Saidur Rahaman, student of BBA program, university of Rajshahi, who directly helped me to prepare this research paper.

\section{References}

Andaleeb, S.S. (2003). Rejuvenating the Nation's Higher Education System. Proceeding of the workshop organized by international University of Business Agriculture and Technology, Dhaka, Bangladesh

Bangladesh Bureau of Education Information and Statistics (BANBEIS): Directorate of University education, Internet entry: http://www.banbeis. gov.bd/db_bb/university education 1. htm. Retrieved on November, 23, 2011.

Bangladesh University Grants Commission (2008), Annual Report-2008. 
Deabnath. S: "No seats for 1.2 lakh after HSC result" The Daily Star, published on 31 August, 2007.

Mamun, M. Z.and Das, S: “Total Quality Management for Non-Government Universities of Bangladesh" Proceedings of Annual Convention of Bangladesh Society for Total Quality Mnagement in Association with Department of industrial and Production Engineering, BUET, Dhaka, December 3-4, 1999, pp. 23-29, 1999.

Majid A.K.M.S, Mamun, M.Z and siddique, S.R. "Practice of Teaching Methods, Aids and Students, Performance Evaluation" 2000.

K.H. Rezwanul et all, "Higher Education in private university of Bangladesh: A study on female students Matriculation Behavior" BRAC university journal, Vol, Vi, No: 2, 2009, page 33-48.

Kitamura, Y: "Expansion and Quality in Bangladesh" Internet entry: http://www.bc.edu/bc org/avp/soe/cihe/new sletter/Number44/p23 kitamura.htm, 2006, retrieved on July 23, 2008.

Salahuddin et all: "How can we increase the quality of private school in Bangladesh from the perspectives of students and Manageres? International journal of Management Perspectives ISSN: 1307-1629, 2008, 2(1), 2008.

Schofield, A:" Private Post- Secondary Education in Four Commonwealth Countries" Paris, UNESCO, 1996.

Tisdell, C.A. and Hossain M.A "Closing gender gap in Bangladesh: inequality in education, employment and earnings" International Journal of Social Economics; Vol. 32, No 5. Page 439-453, 2005

Zahid, J. R. Chowdhury G.M.and Sogra J. "Present Status and Future Direction of Business Education in Bangladesh" Journal of Business Administration, 26, pp. 11-24, 2000.

Appendix: 02 Name of the university from which data were collected

\begin{tabular}{|c|l|c|}
\hline Division & \multicolumn{1}{|c|}{ Name of the University } & $\begin{array}{c}\text { Number of } \\
\text { Respondents }\end{array}$ \\
\hline \multirow{5}{*}{ Dhaka } & Ahsanullah University of Science and Technology & $\mathbf{5 0}$ \\
\cline { 2 - 3 } & ASA University Bangladesh & $\mathbf{5 0}$ \\
\cline { 2 - 3 } & Atish Dipankar University of Science and Technology & $\mathbf{5 0}$ \\
\cline { 2 - 3 } & Independent University, Bangladesh & $\mathbf{5 0}$ \\
\cline { 2 - 3 } & Northern University, Bangladesh & $\mathbf{5 0}$ \\
\cline { 2 - 3 } & Asian University of Bangladesh & $\mathbf{5 0}$ \\
\cline { 2 - 3 } & Bangladesh University of Business and Technology & $\mathbf{5 0}$ \\
\cline { 2 - 3 } & Green University of Bangladesh & $\mathbf{5 0}$ \\
\hline \multirow{5}{*}{ Sylhet } & Metropolitan University, Sylhet & $\mathbf{5 0}$ \\
\cline { 2 - 3 } & Leading University, Sylhet & $\mathbf{5 0}$ \\
\cline { 2 - 3 } & Sylhet International University. & $\mathbf{5 0}$ \\
\hline \multirow{5}{*}{ Chittagong } & International Islamic University, Chittagong & $\mathbf{5 0}$ \\
\cline { 2 - 3 } & Premier University, Chittagong & $\mathbf{5 0}$ \\
\cline { 2 - 3 } & University of Science and Technology, Chittagong & $\mathbf{5 0}$ \\
\hline Rajshahi & University of Information Technology and Sciences & \\
\hline
\end{tabular}




\section{Appendix: 01 Results found from the SPSS analysis}

$\mathrm{Y}($ Stu_Enr $)=\beta \mathbf{i}+\beta 1($ Par_Cam $)+\beta 2($ Loc_Cam $)+\beta 3($ Lib_Fac $)+\beta 4($ Parn_Dec $)+\beta 5$ $($ Com_Lab) $+\beta 6$ (Img_uni) $+\beta 7$ (Pre_Prog) $+\beta 8$ (Cls_Fac) $+\beta 9$ (Can_Fac) $+\beta 10$ (Com_Fac) $+\beta 11$ (Lab_Fac) $+\beta 12$ (Host_Fac) $\beta 1+\beta 13$ (Ind_Fac) $+\beta 14$ (Pray_Fac) $+\beta 15$ (Med_Fac) + $\beta 16$ (Tran_Fac) $+\beta 17$ (Audit_Fac) $+\beta 18$ Crd_Tran $)+\beta 19($ Cul_Club $)+\beta 20($ Sta_VC $)+\beta 21$ $($ N.Qul_Tc $)+\beta 22$ (Maj_Sub) $+\beta 23$ (Dis_Room) $+\beta 24$ (Wash_Room $)+\beta 25$ (Tut_Fees)

\begin{tabular}{|l|c|c|c|c|c|}
\hline \multicolumn{1}{|c|}{$\begin{array}{c}\text { Mode } \\
\text { I }\end{array}$} & \multicolumn{2}{|c|}{$\begin{array}{c}\text { Unstandardized } \\
\text { Coefficients }\end{array}$} & $\begin{array}{c}\text { Standardized } \\
\text { Coefficients }\end{array}$ & $\mathbf{t}$ & Sig \\
\hline 1 & $\mathbf{B}$ & Std. Error & Beta & & \\
(Constant) & .232 & .145 & & & \\
Par_Cam & -.005 & .010 & -.005 & -.445 & .656 \\
Loc_Cam & .001 & .008 & .001 & .121 & .904 \\
Lib_Fac & .002 & .006 & .004 & .375 & .708 \\
Parn_Dec & .004 & .010 & .004 & .389 & .698 \\
Com_Lab & .009 & .005 & .019 & 1.806 & .071 \\
Img_uni & .959 & .011 & .957 & 89.961 & .000 \\
Pre_Prog & -.010 & .014 & -.010 & -.728 & .467 \\
Cls_Fac & -.013 & .009 & -.016 & -1.533 & .126 \\
Can_Fac & .004 & .005 & .007 & .673 & .501 \\
Com_Fac & .006 & .006 & .011 & 1.000 & .318 \\
Lab_Fac & -.001 & .006 & -.002 & -.212 & .832 \\
Host_Fac & -.019 & .011 & -.021 & -1.788 & .074 \\
Ind_Fac & -.004 & .005 & -.008 & -.742 & .458 \\
Pray_Fac & -.014 & .007 & -.025 & -2.125 & .034 \\
Med_Fac & -.074 & .030 & -.147 & -2.462 & .014 \\
Tran_Fac & -.011 & .010 & -.012 & -1.136 & .256 \\
Audit_Fac & -.001 & .005 & -.002 & -.162 & .871 \\
Crd_Tran & .021 & .012 & .023 & 1.702 & .089 \\
Cul_Club & .067 & .030 & .134 & 2.237 & .026 \\
Sta_VC & -.014 & .011 & -.013 & -1.241 & .215 \\
N.Qul_Tc & .026 & .011 & .028 & 2.376 & .018 \\
Maj_Sub & -.006 & .006 & -.011 & -1.072 & .284 \\
Dis_Room & .012 & .005 & .025 & 2.340 & .020 \\
Wash_Room & .004 & .005 & .008 & .701 & .483 \\
Tut_Fees & .009 & .010 & .010 & .889 & .374 \\
\hline
\end{tabular}

